\title{
Adolescent Corticosterone and TrkB Pharmaco-Manipulations Sex-Dependently Impact Instrumental Reversal Learning Later in Life
}

\author{
Elizabeth T. Barfield ${ }^{1,2,3,4}$ and Shannon L. Gourley 1,2,3,4* \\ ${ }^{1}$ Department of Pediatrics, Emory University, Atlanta, GA, United States, ${ }^{2}$ Graduate Program in Neuroscience, Emory \\ University, Atlanta, GA, United States, ${ }^{3}$ Yerkes National Primate Research Center, Emory University, Atlanta, GA, \\ United States, ${ }^{4}$ Department of Psychiatry and Behavioral Sciences, Emory University, Atlanta, GA, United States
}

\section{OPEN ACCESS}

Edited by:

Nuno Sousa,

Instituto de Pesquisa em Ciências da Vida e da Saúde (ICVS), Portugal

Reviewed by:

Alicia Izquierdo,

University of California, Los Angeles, United States

Nicholas W. Simon,

University of Pittsburgh, United States

Caitlin Anne Orsini,

University of Florida, United States

*Correspondence:

Shannon L. Gourley shannon.I.gourley@emory.edu

Received: 28 July 2017 Accepted: 14 November 2017 Published: 07 December 2017

Citation:

Barfield ET and Gourley SL (2017) Adolescent Corticosterone and TrkB Pharmaco-Manipulations Sex-Dependently Impact Instrumental Reversal Learning Later in Life. Front. Behav. Neurosci. 11:237. doi: 10.3389/fnbeh.2017.00237
Early-life trauma can increase the risk for, and severity of, several psychiatric illnesses. These include drug use disorders, and some correlations appear to be stronger in women. Understanding the long-term consequences of developmental stressor or stress hormone exposure and possible sex differences is critically important. So-called "reversal learning" tasks are commonly used in rodents to model cognitive deficits in stress- and addiction-related illnesses in humans. Here, we exposed mice to the primary stress hormone corticosterone (CORT) during early adolescence (postnatal days 31-42), then tested behavioral flexibility in adulthood using an instrumental reversal learning task. CORT-exposed female, but not male, mice developed perseverative errors. Despite resilience to subchronic CORT exposure, males developed reversal performance impairments following exposure to physical stressors. Administration of a putative tyrosine kinase receptor B (trkB) agonist, 7,8-dihydroxyflavone (7,8-DHF), during adolescence blocked CORT-induced errors in females and improved performance in males. Conversely, blockade of trkB by ANA-12 impaired performance. These data suggest that trkB-based interventions could have certain protective benefits in the context of early-life stressor exposure. We consider the implications of our findings in an extended "Discussion" section.

\section{Keywords: juvenile, impulsivity, BDNF, tropomyosin receptor kinase B, 7,8-dihydroxyflavone}

\section{INTRODUCTION}

Reversal tasks assess the ability of mice or rats to flexibly modify behaviors when reinforcement contingencies change. These tasks are commonly used to model behavioral inflexibility associated with addiction and other disorders in humans (for recent review Izquierdo et al., 2017). Typically, animals are trained to associate specific actions or stimuli with reward (e.g., food), then, the association is modified such that a previously non-predictive contingency could be used to obtain reinforcement, while the original contingency is no longer predictive. Thus, these tasks require animals to inhibit a familiar response strategy and deploy a new strategy to obtain reinforcement.

Behavioral inflexibility in these tasks may result from (Ersche et al., 2008; Jentsch et al., 2002; Schoenbaum et al., 2004) and also predispose organisms to (Dalley et al., 2007; Belin et al., 2008; Groman et al., 2009) drug-seeking behaviors. For example, in humans, deficits in reversal 
learning correlate with the severity of cocaine use (MorenoLópez et al., 2015), and a "behavioral disinhibition" trait is associated with later substance use disorders (Tarter et al., 2004; Nigg et al., 2006). Further, rats or mice exhibiting low inhibitory control over impulsive responding more rapidly escalate rates of cocaine self-administration and are more prone to developing drug taking characterized as compulsive (Dalley et al., 2007; Belin et al., 2008; Cervantes et al., 2013). Thus, individual differences in behavioral flexibility and inhibitory control may influence the progression from initial drug use to habitual or compulsive drug-seeking (Cervantes et al., 2013).

Adverse experiences early in life are linked with negative psychiatric outcomes in adulthood, including increased risk for drug use disorders (Fergusson et al., 1996; Kessler et al., 1997; Dube et al., 2003; Green et al., 2010; Afifi et al., 2012) and greater lifetime severity of substance abuse (Hyman et al., 2006; Sacks et al., 2008; Enoch, 2011). Furthermore, several studies report that this association is stronger in women (Widom and White, 1997; MacMillan et al., 2001; Simpson and Miller, 2002; Hyman et al., 2008). The neurobehavioral processes that translate developmental stressor exposure into psychiatric vulnerabilities later in life are incompletely understood, but may involve disruption of prefrontal cortex (PFC)-dependent executive functions, such as behavioral flexibility and inhibitory control (Elton et al., 2014). Indeed, early-life trauma is associated with deficits in inhibitory control (Lewis et al., 2007; Mueller et al., 2010; Skowron et al., 2014; Marshall et al., 2016), and in at least one study, trait impulsivity mediated the relationship between childhood trauma and substance dependence severity in adulthood (Schwandt et al., 2013). Comparing susceptibility to early-life stress-induced inhibitory control deficits between males and females may provide insight into mechanisms of sex differences in risk for stress-related psychopathology.

In the present study, we manipulated levels of the primary glucocorticoid, corticosterone (CORT), and determined long-term consequences in an instrumental reversal task. We exposed mice to exogenous CORT from postnatal day $(\mathrm{P}) 31-42$, corresponding to early adolescence in rodents (Spear, 2000), and a period of considerable structural maturation in the PFC (Shapiro et al., 2017b). Mice were then trained as adults to perform food-reinforced nose poke responses. We found that subchronic CORT exposure induced habit-biased behavior, despite the cessation of CORT exposure, and these findings are reported in Barfield et al. (in press). We then tested mice in an instrumental reversal task, and the results of those tests are reported here.

In some groups, we stimulated tyrosine kinase receptor B (trkB), the high-affinity receptor for brain-derived neurotrophic factor (BDNF), which regulates dendritic spine structure and function (Yoshii and Constantine-Paton, 2010). BDNF-trkB systems are impacted by stress (Gray et al., 2013; Numakawa et al., 2013), implicated in addiction-related behaviors (Li and Wolf, 2015), and significantly modify reward-related decision making (Pitts et al., 2016). Loss of neurotrophic support following prolonged exposure to elevated glucocorticoids is thought to contribute to structural and functional alterations in the PFC that are associated with stress-related psychopathology (Duman et al., 1997). Moreover, recent findings implicate down-regulation of BDNF-trkB signaling in the long-term behavioral consequences of adolescent stress exposure (Xu et al., 2016; Zhang et al., 2017; Barfield et al., in press). Thus, we hypothesized that stimulating trkB may have protective benefits in animals exposed to CORT during adolescence, blocking enduring behavioral deficits.

We report sex-dependent long-term consequences of both CORT and trkB manipulations in an instrumental reversal task. Namely, a history of early-adolescent CORT exposure in females, but not males, induced perseverative responding. Despite apparent resilience to early-adolescent CORT, males developed behavioral inflexibilities following repeated stressor exposure or trkB blockade during early adolescence. Further, a putative trkB agonist improved performance in both sexes. We consider the implications of our findings in an extended "Discussion" section.

\section{MATERIALS AND METHODS}

\section{Subjects}

Subjects were male and female wild-type C57BL/6 mice (Jackson Labs, Bar Harbor, ME, USA) or mice expressing thy1-derived yellow fluorescent protein (YFP; Feng et al., 2000) that were fully back-crossed onto a C57BL/6 background. Mice were not handled, other than for routine veterinary care, until P31. Mice were group-housed, maintained on a 12-h light cycle (0700 on) and provided food and water ad libitum except during instrumental conditioning when body weights were maintained at $90 \%-93 \%$ of baseline to motivate responding. Animal numbers for each experiment are indicated in the respective figure captions. This study was carried out in accordance with the recommendations of the Guide for the Care and Use of Laboratory Animals. The protocol was approved by the Emory University IACUC.

\section{CORT Exposure}

CORT hemisuccinate (4-pregnen-11ß 21-DIOL-3 20-DIONE 21-hemisuccinate; Steraloids) was dissolved in tap water (25 $\mu \mathrm{g} / \mathrm{mL}$ free base; Gourley et al., 2008a,b, 2012b). CORT-exposed mice were given CORT in place of normal drinking water, while control mice consumed tap water. CORT solutions were changed every 3 days. Water bottles were weighed daily, and mice weighed every other day to calculate average doses $(\sim 5-9 \mathrm{mg} / \mathrm{kg} /$ day $)$ of CORT. Mice were exposed to CORT or water from P31 to 42, corresponding to early adolescence in rodents (Spear, 2000). After a 2-week washout period, when mice reached young adulthood (P56), instrumental conditioning began. Timelines are in the figures.

\section{Forced Swim Stress}

Mice were exposed to forced swim stress daily from P31 to 42 . Mice were placed in a glass cylinder $(24 \mathrm{~cm} \times 15.5 \mathrm{~cm}$ 
diameter) filled with $25^{\circ} \mathrm{C}$ water in a dimly lit room. After $6 \mathrm{~min}$, mice were dried in a warm cage lined with paper towels, then returned to the home cage. Water was changed between mice. Control mice were handled but not exposed to swim stress.

\section{Instrumental Conditioning}

Mice were trained to nose poke for food reinforcement $(20 \mathrm{mg}$ grain-based pellets; Bio-Serv, Flemington, NJ, USA) using Med Associates conditioning chambers equipped with two nose-poke recesses, a retractable lever, and a food magazine. Responding on each of two nose-poke recesses was reinforced using a fixed ratio 1 (FR1) schedule of reinforcement; 30 reinforcers were available for responding on each aperture, resulting in 60 reinforcers/session. Sessions ended when mice acquired all 60 reinforcers or at $70 \mathrm{~min}$. Five to seven daily training sessions were conducted. Response acquisition curves represent both nose poke responses/min. Mice were then tested in an instrumental contingency degradation task, followed by a reversal task (see timeline in Figure 1A). Given our focus on reversal conditioning here, only reversal performance is shown.
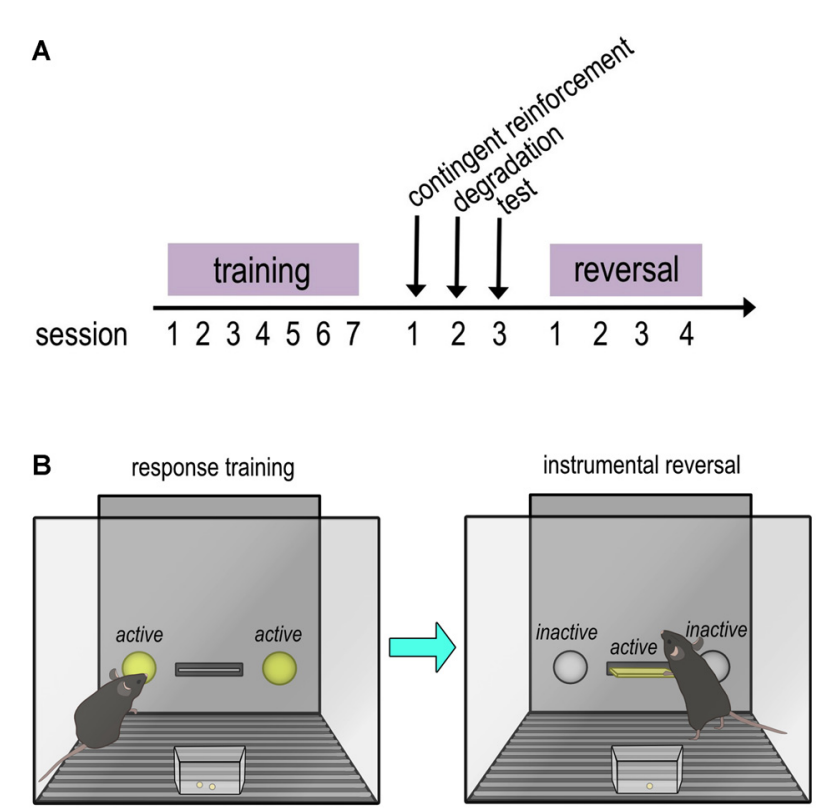

FIGURE 1 | Timeline and schematic of instrumental training and reversal task. (A) Timeline of training and tasks. Mice were trained to nose poke in operant conditioning chambers for food reinforcers. Next, an action-outcome contingency degradation task was performed, in which the contingency between an action and outcome are "degraded" by providing food pellets independently of the mouse's actions. The data from these tests are reported in Barfield et al. (in press). An instrumental reversal task followed, and the data from these tests are reported in the present manuscript. (B) Schematic of response training and instrumental reversal. In the instrumental reversal task, the reinforced response was "reversed" from a nose poke on the sides of the chamber to a lever press located in the center of the chamber that had not previously been available. Acquisition of the newly reinforced response (lever press) and inhibition of the previously reinforced response (nose poke) were measured over multiple sessions.

\section{Instrumental Reversal Test}

In this task, the reinforced response was "reversed" to a lever press; there were no consequences for generating the previously reinforced nose poke response (Figure 1B). Lever pressing was reinforced using an FR1 schedule, with one 25-min session/day for four consecutive days. Lever press rates reflect acquisition of a new response, while nose poke rates reflect inhibition of the previously reinforced response. The percent of correct responses made during session 1 was calculated by dividing total lever presses by total responses (lever presses + nose pokes).

\section{Drugs (Dosing and Timing)}

Male and female mice were administered (i.p.) the putative trkB agonist, 7,8-dihydroxyflavone (7,8-DHF; Sigma; $3 \mathrm{mg} / \mathrm{kg}$; dissolved in 17\% DMSO and saline; Zhang et al., 2014), or vehicle daily from P39 to 47, overlapping with the end of the adolescent CORT exposure period. This period is marked by significant pruning of dendritic spines on excitatory pyramidal neurons in the mouse orbital PFC (oPFC; Shapiro et al., 2017b). Additionally, expression levels of trkB in the oPFC increase during this time (Shapiro et al., 2017b), potentially facilitating activity-dependent refinement of synaptic connections and stabilizing synapses that are not pruned. This period was also determined based on prior work (Barfield et al., in press).

The trkB antagonist, ANA-12 (Sigma; $0.5 \mathrm{mg} / \mathrm{kg}, 1 \%$ DMSO), or vehicle was administered (i.p.) daily from P31 to 42 , to match the period of adolescent CORT exposure.

\section{Statistical Analyses}

Two-tailed statistical analyses with $\alpha \leq 0.05$ were performed using SPSS. Response rates were compared by two-factor (group $\times$ session) or three-factor $(\mathrm{CORT} \times 7,8-\mathrm{DHF} \times$ session $)$ mixed analysis of variance (ANOVA) with session as a within-subjects (repeated measure) factor. Tukey's post hoc tests were used following interactions or main effects between greater than two groups, and results are indicated graphically. The percent of responses that were reinforced ("correct") were compared by one-factor or two-factor $($ CORT $\times 7,8$-DHF) ANOVA or Student's $t$-tests. In additional comparisons, CORT-exposed mice were split into "vulnerable" and "non-vulnerable" groups based on a median split of percent correct values from session 1 of the instrumental reversal task. Throughout, values $>2$ SDs from the mean were excluded.

\section{RESULTS}

\section{Early-Adolescent Corticosteroid Exposure in Females Impairs Response Inhibition in Adulthood}

We exposed female and male mice to CORT in the drinking water from P31 to 42, equivalent to early adolescence in humans (Spear, 2000). Some mice also received daily i.p. injections of vehicle (17\% DMSO and saline) or $7,8-\mathrm{DHF}$ (3 $\mathrm{mg} / \mathrm{kg}$ ) from P39 to P47. In the interest of clarity, only 
vehicle-treated and non-injected mice are shown in Figure 2, and then all injected groups are represented in Figures 3, 4, respectively.

As adults, female mice acquired the nose poke responses without group differences (main effect and interaction $F \mathrm{~s}<1$; Figure 2A). When the response requirement was "reversed" to a lever press, females with a history of adolescent CORT exposure made more perseverative errors than control mice-responding on the previously reinforced nose poke apertures despite nonreinforcement-during session 1 (interaction $F_{(3,69)}=4.0$, $p=0.01$; Figure 2B). Meanwhile, acquisition of the newly reinforced lever response was unaffected (main effect and interaction $F$ s $<1$; Figure 2C).

We also calculated the percentage of total responses that were reinforced during session 1 . While this measure did not significantly differ between groups $t_{(23)}=1.3$, $p=0.2$; Figure 2D), mice with a history of CORT exposure qualitatively appeared to segregate into two groups. As an exploratory analysis, we applied a median split to CORT mice. CORT-exposed "vulnerable" mice made significantly fewer correct responses relative to both control and CORT-exposed "non-vulnerable" mice (main effect group $F_{(2,22)}=11.1$, $p<0.001$; Figure 2E). Thus, in females, a history of CORT exposure during early adolescence increases perseverative errors, and considerable individual differences are noted.

We repeated this experiment in male mice. Mice acquired the food-reinforced nose poke responses in adulthood, without group differences (main effect and interaction $F_{S}<1$; Figure 2F). In contrast to females, early-adolescent CORT exposure in males did not impact response reversal (errors, main effect and interaction $F$ s $<1$; Figure 2G; lever response acquisition, main effect and interaction $F$ s $<1$; Figure $2 \mathbf{H}$ ). There were no differences in the percentage of responses that were reinforced $\left(t_{(12)}=0.8, p=0.5\right.$; Figure 2I), and a median split of values revealed no differences between control mice and either of the two CORT-exposed subgroups (main effect group $F_{(2,11)}=2.0, p=0.2$; Figure 2J). Thus, females may be especially vulnerable to the long-term effects of CORT exposure during early adolescence on response inhibition.
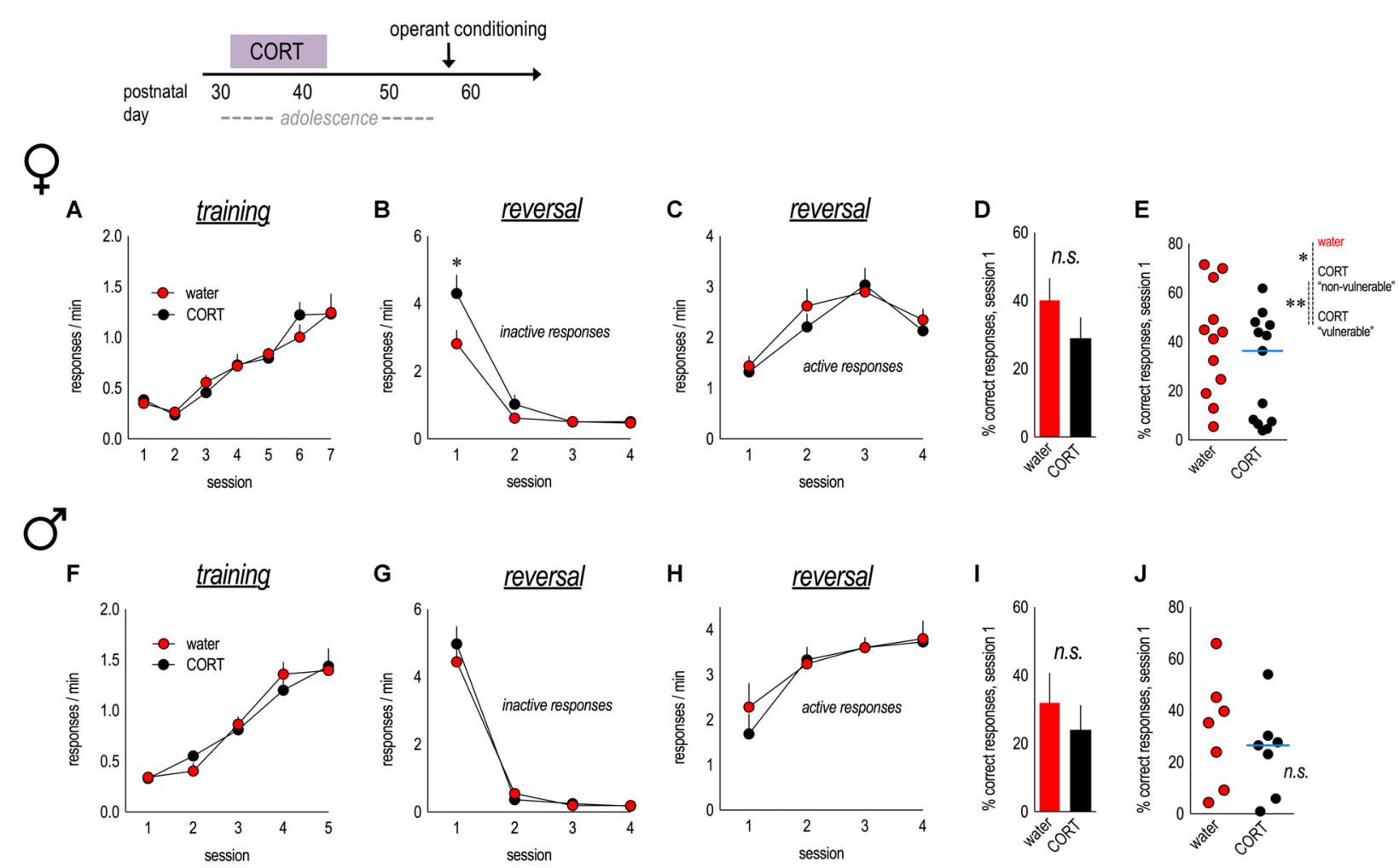

FIGURE 2 | Corticosterone (CORT) exposure in adolescent females induces reversal errors in adulthood. An experimental timeline is at top. (A) Female mice with a history of CORT exposure were trained to nose poke for food reinforcers, with no group differences. (B) In an instrumental reversal task, CORT-exposed mice made more perseverative errors, generating the previously-reinforced response. (C) CORT did not impact the acquisition of the new lever press response. (D) The percent of correct responses made during session 1 did not differ between groups. (E) However, a median split revealed that CORT-exposed females separated into two distinct subgroups; the "vulnerable" group made significantly fewer correct responses. $n=12-13 /$ group. (F) Male mice exposed to CORT during adolescence acquired the nose poke responses without group differences. (G) A history of early-adolescent CORT exposure did not impact inhibition of the previously reinforced, now-inactive, response. (H) Acquisition of the newly reinforced response was also not impacted. (I,J) The percent of correct responses made during session 1 also did not differ between groups. $n=7$ /group. Symbols and bars represent means + SEMs, except for scatter plots, where symbols represent individual mice, and blue lines indicate the median. ${ }^{*} p \leq 0.05$. ${ }^{* *} p \leq 0.001$. 

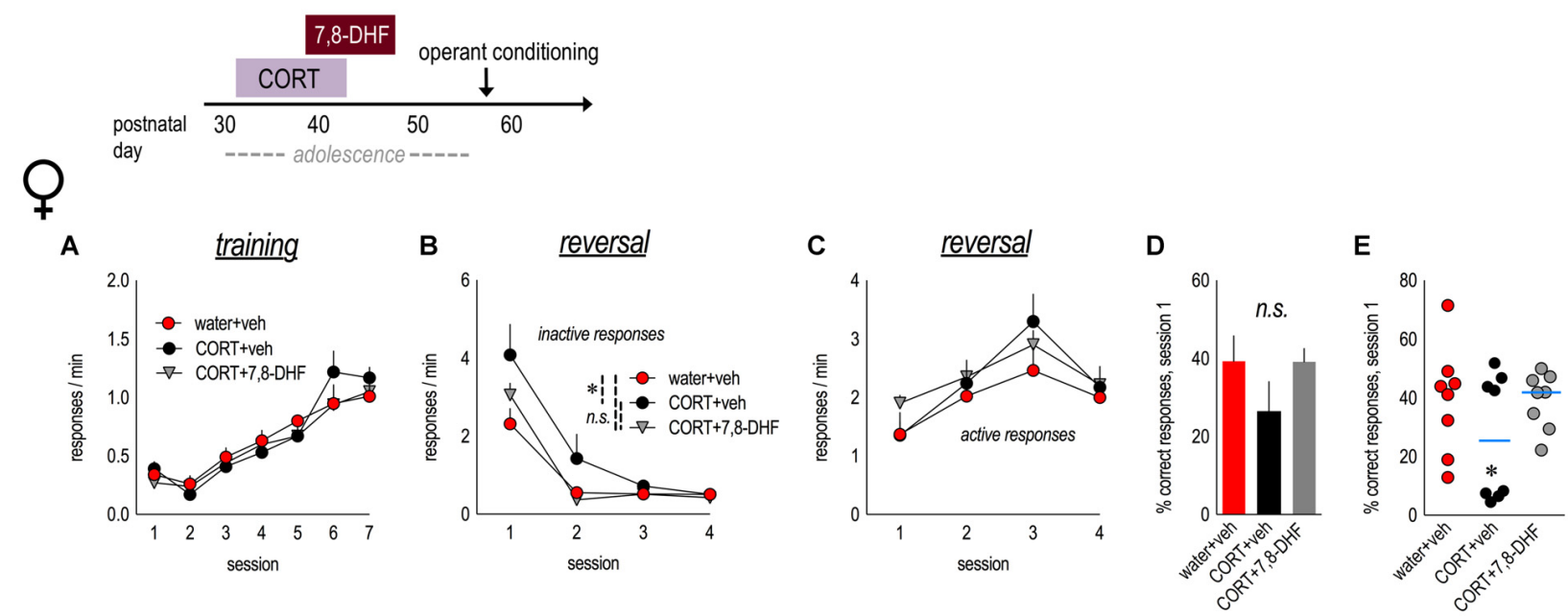

FIGURE 3 | Tyrosine kinase receptor B (TrkB) stimulation blocks perseverative errors in CORT-exposed female mice. Experimental timeline is at top. Female mice were exposed to CORT from P31 to 42 and administered the trkB agonist, 7,8-dihydroxyflavone (7,8-DHF), from P39 to 47. (A) As adults, mice were trained to nose poke for food reinforcers, with no differences between groups. (B) CORT-exposed mice made more perseverative errors, and 7,8-DHF mitigated this effect.

(C) Groups generated the newly reinforced response at similar rates. (D) There were no gross effects on the percent of correct responses made during session 1.

(E) CORT-exposed mice were divided into two subgroups on the basis of a median split of percent values, revealing two populations, including a subgroup that made significantly fewer correct responses. 7,8-DHF eliminated these differences. $n=8$ /group. Symbols and bars represent means + SEMs. ${ }^{*} p \leq 0.05$.

\section{TrkB Stimulation Blocks CORT-Induced Errors}

We attempted to block the long-term behavioral consequences of adolescent CORT exposure in females by administering 7,8-DHF ( $3 \mathrm{mg} / \mathrm{kg}$ ) during mid-adolescence (P39-47). A 7,8-DHF-only group was omitted to conserve animal usage. We found no group differences in response acquisition (main effect and interaction $F s<1$; Figure 3A). As before, mice with a history of adolescent CORT exposure generated more non-reinforced responses in reversal (main effect group $F_{(2,21)}=3.6, p=0.046$; session $\times$ group interaction $\left.F_{(6,63)}=2.1, p=0.07\right)$, and treatment with 7,8-DHF mitigated this impairment in response inhibition (Figure 3B). Acquisition of the newly reinforced lever press did not differ (main effect and interaction $F s \leq 1$; Figure $3 \mathrm{C}$ ). Groups did not differ in the percentage of responses that were reinforced during session 1 (main effect group $F_{(2,21)}=1.5$, $p=0.3$; Figure 3D). Further, treatment with 7,8-DHF eliminated the existence of "vulnerable" and "non-vulnerable" populations within the CORT-exposed group (ANOVA with CORT+vehicle and CORT+7,8-DHF mice separated into two subgroups based on a median split (five groups total): main effect group $F_{(4,19)}=7.9, p=0.001$; Figure $3 \mathrm{E}$ ). Thus, a trkB agonist occludes long-term deficits in response inhibition following early-life CORT exposure.

\section{TrkB Stimulation in Adolescence Improves Behavioral Flexibility in Adulthood}

Male mice exposed to water or CORT during early adolescence were also administered either vehicle or 7,8-DHF. As adults, all mice acquired the nose poke responses for food reinforcement, without group differences (main effect and interaction $F s \leq 1.2$;
Figure 4A). In instrumental reversal, a history of CORT exposure did not impact response inhibition $\left(F_{\mathrm{S}}<1\right)$ or acquisition of the newly reinforced response $(F s<1)$, as described above. Nevertheless, 7,8-DHF reduced perseverative responding during session 1 in both control and CORT-exposed animals (session $\times 7,8$-DHF interaction $F_{(3,72)}=7.1, p<0.001$; Figure 4B) and increased responding on the newly reinforced lever in session 1 (session $\times 7,8$-DHF interaction $F_{(3,72)}=6.6$, $p=0.001$; Figure 4C). 7,8-DHF also increased the percentage of responses that were correct during session 1 (main effect $F_{(1,24)}=7.7, p=0.01$; CORT $\times 7,8$-DHF interaction $F_{(1,24)}=1.8$, $p=0.2$; Figure 4D), further indicating that stimulation of trkB during adolescence enhances behavioral flexibility in adulthood, well beyond the period of drug treatment.

\section{Adolescent Stressor Exposure and TrkB Inhibition Impair Reversal Performance}

The apparent resilience of male mice to early-adolescent CORT exposure was somewhat surprising, so we exposed another group of males to swim stress during early adolescence (daily from P31 to 42). In adulthood, we detected no group differences in the acquisition of the nose poke responses (main effect $F<1$; interaction $F_{(4,68)}=1.8, p=0.1$; Figure 5A). When mice were required to shift responding to a previously non-reinforced lever, control and stressor-exposed mice did not differ in responding on the previously reinforced nose poke apertures (main effect $F_{(1,16)}=1.3, p=0.3$; interaction $F_{(3,48)}=1.3, p=0.3$; Figure 5B). However, mice with a history of adolescent stressor exposure responded less on the newly reinforced lever (main effect $F_{(1,16)}=8.1, p=0.01$; session $\times$ group interaction $F_{(3,48)}=1.2$, $p=0.3$; Figure 5C), making fewer reinforced responses during 

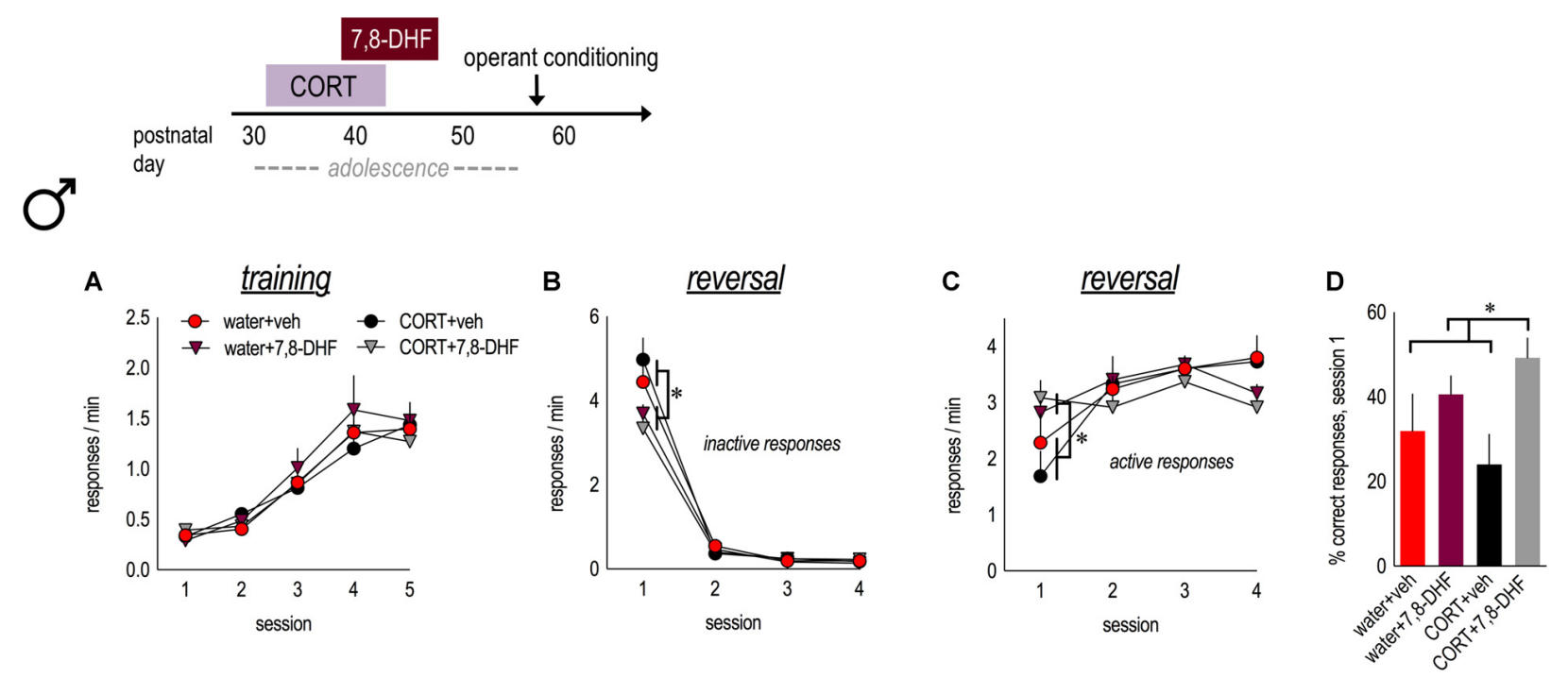

FIGURE 4 | TrkB stimulation during adolescence enhances behavioral flexibility in adulthood. Experimental timeline is at top. Male mice were exposed to CORT from P31 to 42 and administered the trkB agonist, 7,8-DHF, from P39 to 47. (A) Mice acquired the nose poke responses in adulthood, with no group differences. (B) In both water and CORT-exposed mice, 7,8-DHF reduced perseverative errors in the first reversal session. (C) Further, 7,8-DHF increased active response rates on the first day of reversal. (D) 7,8-DHF also increased the percent of correct responses made during session 1 (asterisk signifies a main effect of 7,8-DHF). $n=7 /$ group. Symbols and bars represent means + SEMs. ${ }^{*} p \leq 0.05$.

session $1\left(t_{(17)}=2.3, p=0.04\right.$; Figure 5D). Thus, stressor exposure in early adolescence impairs the ability of male mice to develop novel response strategies in adulthood. This deficiency is similar to those following lateral oPFC (loPFC) ablation (Gourley et al., 2010; summarized in Table 1).

Prolonged stressor or glucocorticoid exposure can down-regulate $B d n f$ or BDNF-trkB signaling in the PFC, and these alterations are associated with impairments in PFC-dependent behavioral tasks (Gourley et al., 2009a, 2012b; Xu et al., 2016; Zhang et al., 2017). Thus, we also tested whether inhibiting trkB during early adolescence would induce reversal deficits in male mice.

Male mice received the trkB antagonist, ANA-12 $(0.5 \mathrm{mg} / \mathrm{kg})$, daily from P31 to 42, matching the period of early-adolescent CORT exposure. As adults, mice acquired the nose poke responses for food reinforcement, without group differences (main effect $F_{(1,12)}=3.6, p=0.08$; interaction $F_{(4,48)}=2.2$, $p=0.09$; Figure 5E). ANA-12 impaired response inhibition (interaction $F_{(3,33)}=10.4, p<0.001$; Figure 5F) and also acquisition (interaction $F_{(3,30)}=4.1, p=0.01$; Figure 5G) during session 1. ANA-12-treated mice made fewer correct responses overall during session $1\left(t_{(12)}=3.1, p=0.01\right.$; Figure $\left.5 \mathbf{H}\right)$. Thus, trkB inhibition during adolescence recapitulated the effects of CORT exposure in females (perseverative responding) and also stressor exposure in males (response acquisition impairments). Our findings are summarized in Table $\mathbf{1 .}$

\section{DISCUSSION}

Adolescents who experience chronic stress have higher incidences of stress-related psychiatric illnesses and behaviors associated with addiction as adults. These behaviors may result in part from disruption of the PFC-dependent ability to flexibly modify behavior when environmental contingencies change (Elton et al., 2014; Zhang et al., 2016; see for review Watt et al., 2017). BDNF signaling through trkB regulates cellular maturational processes occurring in the PFC during adolescence (Xu et al., 2000; Shapiro et al., 2017b), and is disrupted by exposure to stress or elevated glucocorticoids (Bath et al., 2013; Numakawa et al., 2013; Suri and Vaidya, 2013). Using an oPFC-dependent instrumental reversal task in mice (see Gourley et al., 2010), we evaluated the long-term consequences of adolescent exposure to CORT, physical stress, $\operatorname{trkB}$ stimulation, or $\operatorname{trkB}$ inhibition, on behavioral flexibility. In females, adolescent CORT exposure increased perseverative errors in adulthood, and this was blocked by a trkB agonist. By contrast, behavioral flexibility was not impacted by CORT exposure in males, but was enhanced by trkB stimulation, as in females. Males did, however, develop reversal deficits in adulthood following repeated stressor exposure or trkB antagonism during adolescence. These findings add to evidence that adverse events or elevated glucocorticoid levels during adolescence can impair behavioral flexibility later in life. Moreover, our data suggest that trkB-based interventions may prevent adolescent stress-related behavioral impairments later in life.

\section{Long-Term, Sex-Dependent Behavioral Consequences of Adolescent CORT Exposure}

The majority of rodent studies examining the long-term neurobehavioral effects of early-life adversity have utilized male subjects, despite evidence for sex differences in the 

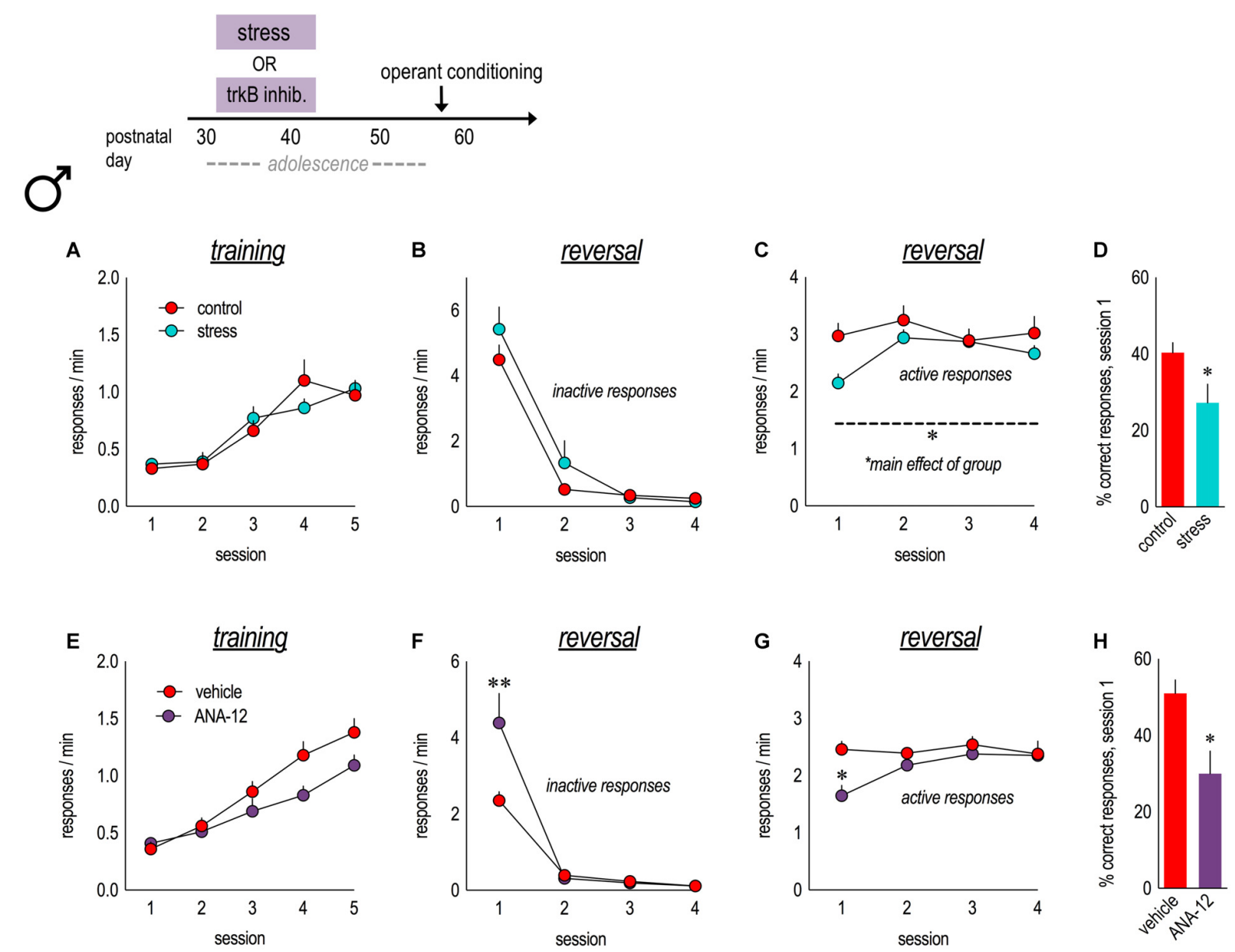

FIGURE 5 | Physical stressors and pharmacological inhibition of trkB in adolescence impair instrumental reversal in adulthood. Experimental timeline is at top. (A) A history of stressor exposure did not impact responding for food reinforcement during training in adulthood. (B) In an instrumental reversal task, both groups performed the now-inactive nose poke response at similar rates. (C) By contrast, stressor-exposed mice performed the now-active lever press response at lower rates. (D) Adolescent stressor exposure also reduced the percent of correct responses made during session 1. $n=9-10 /$ group. (E) In parallel experiments, mice received daily injections of the trkB antagonist, ANA-12, from P31 to 42. Mice learned to nose poke for food reinforcement in adulthood, with no group differences. (F) TrkB blockade during adolescence increased perseverative errors during the first reversal session. (G) ANA-12 also reduced responding on the now-active lever during session 1. (H) ANA-12-treated mice made fewer correct responses during session 1. $n=7 /$ group. Symbols and bars represent means + SEMs. ${ }^{*} p \leq 0.05$. ${ }^{* *} p \leq 0.001$.

prevalence and severity of stress-related psychiatric illnesses (Kessler et al., 1993; MacMillan et al., 2001; Holbrook et al., 2002; Kuehner, 2003; Becker et al., 2012; Fattore et al., 2014). We report that CORT dissolved in the drinking water of mice during a period equivalent to early adolescence in humans (P31-42; Spear, 2000) impaired performance in an instrumental reversal task in adulthood in female mice, but not males. Specifically, adolescent CORT impaired the inhibition of a previously reinforced response, increasing perseverative errors. Similarly, exposure to stress-level cortisol in young-adult or older-adult female squirrel monkeys increases response inhibition errors in a detour-reaching task that assesses the ability to inhibit prepotent responses when reinforcement contingencies change (Lyons et al., 2000).
We also calculated the percent of responses that were reinforced ("correct") during the first reversal session, revealing a "CORT vulnerable" subgroup (approximately half of the group) with significantly impaired behavioral flexibility relative to a CORT-exposed "non-vulnerable" group and control mice. What mediates this vulnerability is unclear, but one factor may be dopamine D2-family receptors (D2, D3, D4). D2/3 antagonists disrupt reversal performance in monkeys and rodents (Ridley et al., 1981; Kruzich and Grandy, 2004; Floresco et al., 2006; Lee et al., 2007; De Steno and Schmauss, 2009), and variation in D2 receptor density in the ventral PFC (including oPFC; Gourley et al., 2009b) and midbrain (Laughlin et al., 2011) correlates with behavioral flexibility. Furthermore, adolescent stress exposure decreases PFC D2 expression in adulthood (Wright et al., 2008). Whether vulnerabilities to 
TABLE 1 | Failures in response acquisition and errors of perseveration in an instrumental reversal task can be dissociated

\begin{tabular}{|c|c|c|c|}
\hline Manipulation & Region & Sex & Reference \\
\hline \multicolumn{4}{|l|}{ Impairments of response acquisition } \\
\hline Early-adolescent forced swim stress & $\mathrm{n} / \mathrm{a}$ & M & Figure $5 \mathrm{C}$ \\
\hline Early-adolescent trkB antagonism & $\mathrm{n} / \mathrm{a}$ & M & Figure 5G \\
\hline Lesion & IOPFC & M & Gourley et al. (2010) \\
\hline Inhibition of Abl-family kinases & IOPFC & M & Gourley et al. (2012a) \\
\hline Bdnf knockdown & IOPFC & M & Gourley et al. (2013a) \\
\hline Disconnection of the loPFC and striatum & IOPFC & M & Gourley et al. (2013a) \\
\hline Early-adolescent trkB antagonism & $\mathrm{n} / \mathrm{a}$ & M & Figure $5 \mathrm{~F}$ \\
\hline Lesion & moPFC+loPFC & M & Boulougouris et al. (2007) \\
\hline Lesion & moPFC & M & Gourley et al. (2010) \\
\hline
\end{tabular}

Errors of perseveration (repeatedly performing an "old" response, despite reversal) or response acquisition (failing to develop a new strategy) can be dissociated in reversal tasks that rely on spatial or instrumental learning and memory. Here we detected failures in response acquisition and errors of perseveration (highlighted in blue). These deficits are associated with manipulations of the lateral OPFC (IOPFC) and medial OPFC (moPFC), respectively (highlighted in gray).

corticosteroid-related modifications in dopamine D2 levels influence the behavioral patterns reported here could be tested in future experiments.

In contrast to females, males exposed to early-adolescent CORT failed to develop instrumental reversal impairments in adulthood. However, some studies report long-term deficits in reversal learning and extradimensional set-shifting (EDS; a medial PFC (mPFC)-dependent function) in male rodents following social stress during early adolescence (Snyder et al., 2015; Zhang et al., 2016). Accordingly, daily forced swim stress during early adolescence (P31-42) impaired the acquisition of the "reversed" response contingency here, resembling the effects of loPFC lesions (Gourley et al., 2010). These findings suggest that in males exposed to repeated stress during adolescence, components of the stress response besides elevations in CORT (e.g., increased noradrenergic tone) may be responsible for response acquisition deficiencies. Indeed, under conditions of chronic stress in adult rats, stress-induced release of norepinephrine in the mPFC impairs certain forms of behavioral flexibility, while noradrenergic receptor blockade in the mPFC prevents stressinduced deficits (Jett and Morilak, 2013). On the other hand, 3 weeks of CORT exposure in adolescent male mice causes errors in a similar instrumental reversal task (Shapiro et al., 2017a), indicating that males are not entirely resilient to CORT.

One possibility is that higher concentrations of CORT would have triggered reversal deficiencies in males. Females have higher basal CORT levels than males, an effect that develops during puberty (Netherton et al., 2004; McCormick and Mathews, 2007; Stroud et al., 2011). Because puberty in rodents typically occurs around P35 in females and P40 in males (Korenbrot et al., 1977; Evans, 1986), administering exogenous CORT during a time when endogenous levels in females are increasing may result in higher total CORT levels in females. While we did not measure blood serum CORT in these experiments, it is possible that recapitulating "female-like" CORT levels in males may have induced comparable behavioral inflexibility.
Because the PFC undergoes significant structural remodeling during adolescence, and PFC-dependent cognitive functions continue to develop throughout this period, prolonged stressor or CORT exposure during adolescence may be more impactful than exposure in adulthood. Consistent with this possibility, male rats exposed to 5 days of social defeat stress during early adolescence (P28-32), then housed in isolation, exhibit deficits in EDS and reversal learning in an attentional set-shifting task 6 weeks later. However, rats exposed to the same stress in mid-adolescence (P38-47) or adulthood (P70-79) do not show these cognitive impairments (Zhang et al., 2016). Furthermore, adolescent stress- or CORT-induced alterations in PFC neuronal morphology, like behavioral deficits, can persist into adulthood. For example, social isolation stress during early adolescence (P30-35) in male rats reduces synaptic density in the mPFC in adulthood (Leussis et al., 2008), suggestive of a long-term loss of dendritic spines, which house the majority of excitatory synapses in the brain. Gourley et al. (2013b) also reported dendritic spine loss on pyramidal neurons in the oPFC immediately following CORT exposure during adolescence (P35-56) that is still evident 1 week after the cessation of CORT. Meanwhile, CORT-induced spine changes in the infralimbic mPFC, hippocampus, and amygdala recover. Consistent with these findings in rodents, early-life adversity in humans is associated with reduced oPFC volume and morphological alterations in adulthood (Holz et al., 2015; Teicher and Samson, 2016). Our findings add to these and other studies reporting long-term consequences of stressor or CORT exposure during early adolescence.

\section{TrkB Manipulations in Adolescence Influence Behavioral Flexibility in Adulthood}

One mechanism by which CORT or stressor exposure during adolescence may impact PFC-dependent behaviors later in life is by reducing BDNF-dependent stimulation of trkB (Duman et al., 1997; Blugeot et al., 2011). Consistent with this possibility, the trkB agonist 7,8-DHF blocked perseverative responding 
in females with a history of adolescent CORT exposure. Additionally, while a subgroup of vehicle-treated CORT-exposed females was especially vulnerable to impairments in behavioral flexibility, 7,8-DHF eliminated these individual differences, and in males, 7,8-DHF improved performance above control levels.

How might 7,8-DHF have long-term behavioral consequences? One possibility is that it prevents CORT-induced disruptions in PFC synaptic maturation by augmenting or restoring trkB activity. BDNF and trkB increase in adolescence/young adulthood (Webster et al., 2002; Shapiro et al., 2017b), and BDNF-trkB signaling is critical for the maintenance of stabile dendritic spines in the postnatal brain (Vigers et al., 2012). Chronic stress or CORT exposure can reduce PFC BDNF and trkB (e.g., see Gourley et al., 2009a, $2012 b)$, potentially altering the trajectory of dendritic spine maturation (Leussis and Andersen, 2008; Eiland et al., 2012) and behavioral outcomes. Consistent with this possibility, we found that administration of the trkB antagonist, ANA-12, during early adolescence impaired behavioral flexibility in adulthood.

Our trkB antagonism experiments were performed in males, but it is worth noting that prior reports indicate that knockdown of $B d n f$ beginning in the preadolescent period or in adulthood in female mice produces behavioral consequences that are comparable to, or more severe than, those in male mice. For example, Vigers et al. (2012) report that forebrain-specific knockdown of $B d n f$ (progressive knockdown begins at $\sim \mathrm{P} 21$ ) induces depressive-like immobility in the forced swim test and contextual fear generalization in both male and female adult mice. However, Monteggia et al. (2007) report that this knockdown strategy results in depression-like behavior in female, but not male, mice. Similarly, inducible knockdown of $B d n f$ in adulthood increases susceptibility to stress-induced depression-like behavior in female mice only (Autry et al., 2009).

Recent findings in addition to ours interestingly implicate BDNF-trkB in the long-term behavioral consequences of earlyadolescent stress. Male rats exposed to chronic mild stress (CMS) during early adolescence (P28-37) exhibit impairments in EDS and decreased levels of BDNF protein, the ratio of p-ERK42/44/ERK42/44, and p-CREB in the mPFC 6 weeks after stressor exposure (Zhang et al., 2017). Additionally, EDS is correlated with $\mathrm{p}$-ERK/ERK ratios in $\mathrm{mPFC}$, and the antidepressant duloxetine ameliorates stress-induced alterations in EDS and $\mathrm{mPFC}$ BDNF levels in tandem. Impairing BDNF-trkB signaling can also alter PFC-dependent functions and drug-taking behaviors. For example, mutant mice with disruption of promoter IV-driven (activity-dependent) BDNF expression are impaired in a spatial reversal task (Sakata et al., 2013). Knock-in mice expressing a homolog of the human BDNF gene polymorphism Val66Met, which decreases the activity-dependent release of BDNF (Chen et al., 2004), develop excessive and compulsive alcohol drinking despite adverse consequences, and this phenotype is reversible by a trkB agonist (Warnault et al., 2016). Furthermore, early-life stress decreases $B d n f$ exon IV mRNA in the PFC and increases cocaineinduced conditioned place preference (CPP) in periadolescent (P45) mice (Viola et al., 2016). Interestingly, higher CPP scores correlate with $B d n f$ expression, with higher place preference associated with lower Bdnf. Thus, by disrupting trkB signaling, early-life stress may increase vulnerability to compulsive drug taking.

\section{Broader Considerations: Sex Differences in Reversal Performance}

Here, we found that adolescent CORT-exposed females and adolescent stress-exposed males exhibited impairments in reversal performance in adulthood; however, the specific behavioral impairments were sexually dimorphic_females failed to inhibit the previously reinforced response, while males were unable to acquire a newly reinforced response (summarized in Table 1). In the context of addiction, poor control over perseverative behavior could modulate the progression from recreational drug use to abuse and dependence, increase relapse rates, and impair treatment response (Carroll et al., 2011). Meanwhile, deficits in the acquisition of a "reversed" response contingency could be comparable to impairments in the ability to adjust behavior according to positive feedback and potentially, to substitute new healthy behaviors for maladaptive ones.

The association between early-life trauma and the risk for, and severity of, drug dependence is stronger in women (Widom and White, 1997; MacMillan et al., 2001; Simpson and Miller, 2002; Hyman et al., 2008), and at least one study reports that a greater proportion of stimulant-dependent women, compared to men, have clinically significant "disinhibition" scores prior to stimulant abuse (Winhusen and Lewis, 2013). In that same study, physical abuse was associated with greater disinhibition in women, but not men. Thus, females may be more vulnerable to chronic stress-induced inhibitory control deficits, in line with our findings. Further, Elton et al. (2014) report that childhood maltreatment results in enduring, sex-dependent changes in the functional connectivity of a network mediating inhibitory behavioral control, also in line with sex-dependent effects of adolescent CORT exposure on perseverative responding here. Future work should examine whether adolescent CORT-induced deficits in response inhibition increase vulnerability to compulsive drug taking later in life. CORT exposure during adolescence increases cue-induced reinstatement of ethanol seeking in adult female, but not male, rats (Bertholomey et al., 2016), suggesting that females are especially vulnerable to adolescent CORT-induced neurobehavioral changes that increase susceptibility to drug relapse later in life.

Our findings may also point to sexually dimorphic stressrelated vulnerabilities in specific brain regions, given that lesions of the medial oPFC (moPFC) impair response inhibition in this task (like CORT-exposed females), while loPFC lesions impair response acquisition (like stressor-exposed males; Gourley et al., 2010). These patterns are interesting when considered alongside studies reporting structural changes in the oPFC of substancedependent males and females. For example, cocaine-dependent females and males exhibit decreased cerebral blood flow in the moPFC and loPFC, respectively (Adinoff et al., 2006). Adolescent females with substance dependence exhibit decreased cortical thickness and gray matter volume in regions involved 
in inhibitory control, decision-making, reward, and risk-taking, including the moPFC and dorsolateral PFC (DLPFC; Dalwani et al., 2015; Boulos et al., 2016), while substance-dependent adolescent males show decreased gray matter volume in DLPFC (Dalwani et al., 2011). Regner et al. (2015) report decreased oPFC gray matter volume in abstinent stimulant-dependent women, but not men. However, in a population of predominantly male treatment-seeking individuals with alcohol dependence, loPFC surface area and volume were smaller in individuals who subsequently relapsed in a 1-year period compared to individuals who remained abstinent (Cardenas et al., 2011; Durazzo et al., 2011). Together, these findings suggest that PFC subregions disrupted by both adolescent stress or glucocorticoid exposure and drugs of abuse may be sex-dependent (potentially: loPFC in males and both moPFC and loPFC in females; see Table 1).

\section{CONCLUSION}

PFC dysfunction and associated deficits in inhibitory control and behavioral flexibility are hallmarks of stress-related illnesses, including addiction. Substance-dependent individuals report loss of control over drug use and have difficulty modifying behaviors when reward contingencies change, potentially contributing to persistent drug seeking despite adverse consequences (Garavan and Hester, 2007; Everitt and Robbins, 2016). Being able to implement new strategies to promote behavioral change and control impulsive responses may be critical to treatment response-among cocaine-dependent individuals undergoing cognitive-behavioral therapy, higher impulsivity/risk-taking before treatment is associated with poorer treatment retention and higher relapse rates (Carroll et al., 2011).

Substance-dependent individuals exhibit structural and functional alterations in the oPFC, including blood flow abnormalities (London et al., 2000; Adinoff et al., 2006), decreased gray matter volume (Matochik et al., 2003; Tanabe et al., 2009; Dalwani et al., 2015), and decreased cortical thickness (Boulos et al., 2016). In animal models, adolescent CORT and cocaine exposure result in long-term changes in oPFC neuron structure (Gourley et al., 2012a, 2013b; DePoy et al., 2014, 2016, 2017) that are associated with maladaptive behaviors symptomatic of addiction (Lucantonio et al., 2012). Further, poor inhibitory control may be a predisposing factor for addiction (Jentsch and Taylor, 1999; Tarter et al., 2004; Groman et al., 2009; Moffitt et al., 2011), as is a history of early-life adversity (Fergusson et al., 1996; Kessler et al., 1997; Dube et al., 2003; Green et al., 2010; Afifi et al.,

\section{REFERENCES}

Adinoff, B., Williams, M. J., Best, S. E., Harris, T. S., Chandler, P., and Devous, M. D. (2006). Sex differences in medial and lateral orbitofrontal cortex hypoperfusion in cocaine-dependent men and women. Gend. Med. 3, 206-222. doi: 10.1016/s1550-8579(06) 80209-3

Afifi, T. O., Henriksen, C. A., Asmundson, G. J., and Sareen, J. (2012). Childhood maltreatment and substance use disorders among men and
2012). These and other findings have led to the hypothesis that early-life adversity may affect addiction liability by impairing oPFC-mediated inhibitory control. That is, in individuals with a history of stressor exposure during sensitive developmental periods like adolescence, repeated drug use may further impair inhibitory control, exacerbating the development, persistence, and severity of addiction. Indeed, social stress during adolescence in rats causes binge-like cocaine self-administration in adulthood (Burke and Miczek, 2015).

Using an oPFC-dependent instrumental reversal task, we find that exposure to CORT during early adolescence induces perseverative errors in female, but not male, mice in adulthood. Further, intervention with a $\operatorname{trkB}$ agonist in mid-adolescence, when dendritic spines in the PFC undergo activity-dependent pruning or stabilization (Petanjek et al., 2011; Gourley et al., 2012a; Selemon, 2013; Chung et al., 2017) corrected decision-making strategies in CORT-exposed mice. With the caveat that the sexes were tested in independent cohorts here-precluding direct comparisons between them-we nevertheless argue that further related research may advance our understanding of how sex differences in the neurobehavioral response to adolescent adversities contribute to sex differences in vulnerability to, and clinical course of, stress-related illnesses. Our findings additionally suggest that pharmacotherapies augmenting trkB may ameliorate the enduring consequences of stressful life events occurring in adolescence.

\section{AUTHOR CONTRIBUTIONS}

ETB performed the experiments, analyzed the data and wrote the manuscript. ETB and SLG designed the experiments, interpreted the data and edited the manuscript.

\section{FUNDING}

This work was supported by an National Institutes of Health (NIH) BRAINS award (MH101477) and the National Science Foundation Graduate Research Fellowship Program under grant number DGE-1444932. The Yerkes National Primate Research Center is supported by the Office of Research Infrastructure Programs/OD P51OD011132.

\section{ACKNOWLEDGMENTS}

We thank A. Allen for assisting with injections.

women in a nationally representative sample. Can. J. Psychiatry 57, 677-686. doi: 10.1177/070674371205701105

Autry, A. E., Adachi, M., Cheng, P., and Monteggia, L. M. (2009). Gender specific impact of BDNF signaling on stress-induced depression-like behavior. Biol. Psychiatry 66, 84-90. doi: 10.1016/j.biopsych.2009. 02.007

Barfield, E. T., Gerber, K. J., Zimmermann, K. S., Ressler, K. J., Parsons, R. G., and Gourley, S. L. (in press). Bidirectional regulation of actions and habits by ventral hippocampal trkB and adolescent corticosteroid exposure. PLoS Biol. 
Bath, K. G., Schilit, A., and Lee, F. S. (2013). Stress effects on BDNF expression: effects of age, sex, and form of stress. Neuroscience 239, 149-156. doi: 10.1016/j. neuroscience.2013.01.074

Becker, J. B., Perry, A. N., and Westenbroek, C. (2012). Sex differences in the neural mechanisms mediating addiction: a new synthesis and hypothesis. Biol. Sex Differ. 3:14. doi: 10.1186/2042-6410-3-14

Belin, D., Mar, A. C., Dalley, J. W., Robbins, T. W., and Everitt, B. J. (2008). High impulsivity predicts the switch to compulsive cocaine-taking. Science 320, 1352-1355. doi: 10.1126/science.1158136

Bertholomey, M. L., Nagarajan, V., and Torregrossa, M. M. (2016). Sex differences in reinstatement of alcohol seeking in response to cues and yohimbine in rats with and without a history of adolescent corticosterone exposure. Psychopharmacology 233, 2277-2287. doi: 10.1007/s00213-016 $-4278-\mathrm{x}$

Blugeot, A., Rivat, C., Bouvier, E., Molet, J., Mouchard, A., Zeau, B., et al. (2011). Vulnerability to depression: from brain neuroplasticity to identification of biomarkers. J. Neurosci. 31, 12889-12899. doi: 10.1523/JNEUROSCI.1309 $-11.2011$

Boulos, P. K., Dalwani, M. S., Tanabe, J., Mikulich-Gilbertson, S. K., Banich, M. T., Crowley, T. J., et al. (2016). Brain cortical thickness differences in adolescent females with substance use disorders. PLoS One 11:e0152983. doi: 10.1371/journal.pone. 0152983

Boulougouris, V., Dalley, J. W., and Robbins, T. W. (2007). Effects of orbitofrontal, infralimbic and prelimbic cortical lesions on serial spatial reversal learning in the rat. Behav. Brain Res. 179, 219-228. doi: 10.1016/j.bbr.2007.02.005

Burke, A. R., and Miczek, K. A. (2015). Escalation of cocaine self-administration in adulthood after social defeat of adolescent rats: role of social experience and adaptive coping behavior. Psychopharmacology 232, 3067-3079. doi: 10.1007/s00213-015-3947-5

Cardenas, V. A., Durazzo, T. C., Gazdzinski, S., Mon, A., Studholme, C., and Meyerhoff, D. J. (2011). Brain morphology at entry into treatment for alcohol dependence is related to relapse propensity. Biol. Psychiatry 70, 561-567. doi: 10.1016/j.biopsych.2011.04.003

Carroll, K. M., Kiluk, B. D., Nich, C., Babuscio, T. A., Brewer, J. A., Potenza, M. N., et al. (2011). Cognitive function and treatment response in a randomized clinical trial of computer-based training in cognitive-behavioral therapy. Subst. Use Misuse 46, 23-34. doi: 10.3109/10826084.2011.521069

Cervantes, M. C., Laughlin, R. E., and Jentsch, J. D. (2013). Cocaine self-administration behavior in inbred mouse lines segregating different capacities for inhibitory control. Psychopharmacology 229, 515-525. doi: 10.1007/s00213-013-3135-4

Chen, Z. Y., Patel, P. D., Sant, G., Meng, C. X., Teng, K. K., Hempstead, B. L., et al. (2004). Variant brain-derived neurotrophic factor (BDNF) (Met66) alters the intracellular trafficking and activity-dependent secretion of wild-type BDNF in neurosecretory cells and cortical neurons. J. Neurosci. 24, 4401-4411. doi: 10.1523/JNEUROSCI.0348-04.2004

Chung, D. W., Wills, Z. P., Fish, K. N., and Lewis, D. A. (2017). Developmental pruning of excitatory synaptic inputs to parvalbumin interneurons in monkey prefrontal cortex. Proc. Natl. Acad. Sci. U S A 114, E629-E637. doi: 10.1073/pnas.1610077114

Dalley, J. W., Fryer, T. D., Brichard, L., Robinson, E. S., Theobald, D. E., Laane, K., et al. (2007). Nucleus accumbens D2/3 receptors predict trait impulsivity and cocaine reinforcement. Science 315, 1267-1270. doi: 10.1126/science. 1137073

Dalwani, M., Sakai, J. T., Mikulich-Gilbertson, S. K., Tanabe, J., Raymond, K., McWilliams, S. K., et al. (2011). Reduced cortical gray matter volume in male adolescents with substance and conduct problems. Drug Alcohol Depend. 118, 295-305. doi: 10.1016/j.drugalcdep.2011.04.006

Dalwani, M. S., McMahon, M. A., Mikulich-Gilbertson, S. K., Young, S. E., Regner, M. F., Raymond, K. M., et al. (2015). Female adolescents with severe substance and conduct problems have substantially less brain gray matter volume. PLoS One 10:e0126368. doi: 10.1371/journal.pone.0126368

DePoy, L. M., Allen, A. G., and Gourley, S. L. (2016). Adolescent cocaine self-administration induces habit behavior in adulthood: sex differences and structural consequences. Transl. Psychiatry 6:e875. doi: 10.1038/tp.2016.150

DePoy, L. M., Perszyk, R. E., Zimmermann, K. S., Koleske, A. J., and Gourley, S. L. (2014). Adolescent cocaine exposure simplifies orbitofrontal cortical dendritic arbors. Front. Pharmacol. 5:228. doi: 10.3389/fphar.2014.00228
DePoy, L. M., Zimmermann, K. S., Marvar, P. J., and Gourley, S. L. (2017). Induction and blockade of adolescent cocaine-induced habits. Biol. Psychiatry 81, 595-605. doi: 10.1016/j.biopsych.2016.09.023

De Steno, D. A., and Schmauss, C. (2009). A role for dopamine D2 receptors in reversal learning. Neuroscience 162, 118-127. doi: 10.1016/j.neuroscience.2009. 04.052

Dube, S. R., Felitti, V. J., Dong, M., Chapman, D. P., Giles, W. H., and Anda, R. F. (2003). Childhood abuse, neglect, and household dysfunction and the risk of illicit drug use: the adverse childhood experiences study. Pediatrics 111, 564-572. doi: 10.1542/peds.111.3.564

Duman, R. S., Heninger, G. R., and Nestler, E. J. (1997). A molecular and cellular theory of depression. Arch. Gen. Psychiatry 54, 597-606. doi: 10.1001/archpsyc. 1997.01830190015002

Durazzo, T. C., Tosun, D., Buckley, S., Gazdzinski, S., Mon, A., Fryer, S. L., et al. (2011). Cortical thickness, surface area and volume of the brain reward system in alcohol dependence: relationships to relapse and extended abstinence. Alcohol. Clin. Exp. Res. 35, 1187-1200. doi: 10.1111/j.1530-0277.2011. 01452.x

Eiland, L., Ramroop, J., Hill, M. N., Manley, J., and McEwen, B. S. (2012). Chronic juvenile stress produces corticolimbic dendritic architectural remodeling and modulates emotional behavior in male and female rats. Psychoneuroendocrinology 37, 39-47. doi: 10.1016/j.psyneuen.2011. 04.015

Elton, A., Tripathi, S. P., Mletzko, T., Young, J., Cisler, J. M., James, A. G., et al. (2014). Childhood maltreatment is associated with a sex-dependent functional reorganization of a brain inhibitory control network. Hum. Brain Mapp. 35, 1654-1667. doi: 10.1002/hbm.22280

Enoch, M. A. (2011). The role of early life stress as a predictor for alcohol and drug dependence. Psychopharmacology 214, 17-31. doi: 10.1007/s00213-010 $-1916-6$

Ersche, K. D., Roiser, J. P., Robbins, T. W., and Sahakian, B. J. (2008). Chronic cocaine but not chronic amphetamine use is associated with perseverative responding in humans. Psychopharmacology 197, 421-431. doi: 10.1007/s00213-007-1051-1

Evans, A. M. (1986). Age at puberty and first litter size in early and late paired rats. Biol. Reprod. 34, 322-326. doi: 10.1095/biolreprod34.2.322

Everitt, B. J., and Robbins, T. W. (2016). Drug addiction: updating actions to habits to compulsions ten years on. Annu. Rev. Psychol. 67, 23-50. doi: 10.1146/annurev-psych-122414-033457

Fattore, L., Melis, M., Fadda, P., and Fratta, W. (2014). Sex differences in addictive disorders. Front. Neuroendocrinol. 35, 272-284. doi: 10.1016/j.yfrne.2014. 04.003

Feng, G., Mellor, R. H., Bernstein, M., Keller-Peck, C., Nguyen, Q. T., Wallace, M., et al. (2000). Imaging neuronal subsets in transgenic mice expressing multiple spectral variants of GFP. Neuron 28, 41-51. doi: 10.1016/s0896-6273(00) 00084-2

Fergusson, D. M., Horwood, L. J., and Lynskey, M. T. (1996). Childhood sexual abuse and psychiatric disorder in young adulthood: II. Psychiatric outcomes of childhood sexual abuse. J. Am. Acad. Child Adolesc. Psychiatry 35, 1365-1374. doi: 10.1097/00004583-199610000-00024

Floresco, S. B., Magyar, O., Ghods-Sharifi, S., Vexelman, C., and Tse, M. T. (2006). Multiple dopamine receptor subtypes in the medial prefrontal cortex of the rat regulate set-shifting. Neuropsychopharmacology 31, 297-309. doi: 10.1038/sj. npp. 1300825

Garavan, H., and Hester, R. (2007). The role of cognitive control in cocaine dependence. Neuropsychol. Rev. 17, 337-345. doi: 10.1007/s11065-0079034-x

Gourley, S. L., Kedves, A. T., Olausson, P., and Taylor, J. R. (2009a). A history of corticosterone exposure regulates fear extinction and cortical NR2B, GluR2/3, and BDNF. Neurpsychopharmacology 34, 707-716. doi: 10.1038/npp.2008.123

Gourley, S. L., Koleske, A. J., and Taylor, J. R. (2009b). Loss of dendrite stabilization by the Abl-related gene (Arg) kinase regulates behavioral flexibility and sensitivity to cocaine. Proc. Natl. Acad. Sci. U S A 106, 16859-16864. doi: 10.1073/pnas.0902286106

Gourley, S. L., Kiraly, D. D., Howell, J. L., Olausson, P., and Taylor, J. R. (2008a). Acute hippocampal BDNF restores motivational and forced swim performance after corticosterone. Biol. Psychiatry 64, 884-890. doi: 10.1016/j.biopsych.2008. 06.016 
Gourley, S. L., Wu, F. J., Kiraly, D. D., Ploski, J. E., Kedves, A. T., Duman, R. S., et al. (2008b). Regionally specific regulation of ERK MAP kinase in a model of antidepressant-sensitive chronic depression. Biol. Psychiatry 63, 353-359. doi: 10.1016/j.biopsych.2007.07.016

Gourley, S. L., Lee, A. S., Howell, J. L., Pittenger, C., and Taylor, J. R. (2010). Dissociable regulation of instrumental action within mouse prefrontal cortex. Eur. J. Neurosci. 32, 1726-1734. doi: 10.1111/j.1460-9568.2010. 07438.x

Gourley, S. L., Olevska, A., Warren, M. S., Taylor, J. R., and Koleske, A. J. (2012a). Arg kinase regulates prefrontal dendritic spine refinement and cocaine-induced plasticity. J. Neurosci. 32, 2314-2323. doi: 10.1523/JNEUROSCI.2730-11.2012

Gourley, S. L., Swanson, A. M., Jacobs, A. M., Howell, J. L., Mo, M., DiLeone, R. J., et al. (2012b). Action control is mediated by prefrontal BDNF and glucocorticoid receptor binding. Proc. Natl. Acad. Sci. U S A 109, 20714-20719. doi: 10.1073/pnas.1208342109

Gourley, S. L., Olevska, A., Zimmermann, K. S., Ressler, K. J., Dileone, R. J., and Taylor, J. R. (2013a). The orbitofrontal cortex regulates outcome-based decision-making via the lateral striatum. Eur. J. Neurosci. 38, 2382-2388. doi: 10.1111/ejn.12239

Gourley, S. L., Swanson, A. M., and Koleske, A. J. (2013b). Corticosteroid-induced neural remodeling predicts behavioral vulnerability and resilience. J. Neurosci. 33, 3107-3112. doi: 10.1523/JNEUROSCI.2138-12.2013

Gray, J. D., Milner, T. A., and McEwen, B. S. (2013). Dynamic plasticity: the role of glucocorticoids, brain-derived neurotrophic factor and other trophic factors. Neuroscience 239, 214-227. doi: 10.1016/j.neuroscience.2012.08.034

Green, J. G., McLaughlin, K. A., Berglund, P. A., Gruber, M. J., Sampson, N. A., Zaslavsky, A. M., et al. (2010). Childhood adversities and adult psychiatric disorders in the national comorbidity survey replication I: associations with first onset of DSM-IV disorders. Arch. Gen. Psychiatry 67, 113-123. doi: 10.1001/archgenpsychiatry.2009.186

Groman, S. M., James, A. S., and Jentsch, J. D. (2009). Poor response inhibition: at the nexus between substance abuse and attention deficit/hyperactivity disorder. Neurosci. Biobehav. Rev. 33, 690-698. doi: 10.1016/j.neubiorev.2008. 08.008

Holbrook, T. L., Hoyt, D. B., Stein, M. B., and Sieber, W. J. (2002). Gender differences in long-term posttraumatic stress disorder outcomes after major trauma: women are at higher risk of adverse outcomes than men. J. Trauma 53, 882-888. doi: 10.1097/00005373-200211000-00012

Holz, N. E., Boecker, R., Hohm, E., Zohsel, K., Buchmann, A. F., Blomeyer, D., et al. (2015). The long-term impact of early life poverty on orbitofrontal cortex volume in adulthood: results from a prospective study over 25 years. Neuropsychopharmacology 40, 996-1004. doi: 10.1038/npp.2014.277

Hyman, S. M., Garcia, M., and Sinha, R. (2006). Gender specific associations between types of childhood maltreatment and the onset, escalation and severity of substance use in cocaine dependent adults. Am. J. Drug Alcohol Abuse 32, 655-664. doi: 10.1080/10623320600919193

Hyman, S. M., Paliwal, P., Chaplin, T. M., Mazure, C. M., Rounsaville, B. J., and Sinha, R. (2008). Severity of childhood trauma is predictive of cocaine relapse outcomes in women but not men. Drug Alcohol Depend. 92, 208-216. doi: 10.1016/j.drugalcdep.2007.08.006

Izquierdo, A., Brigman, J. L., Radke, A. K., Rudebeck, P. H., and Holmes, A. (2017). The neural basis of reversal learning: an updated perspective. Neuroscience 345, 12-26. doi: 10.1016/j.neuroscience.2016.03.021

Jentsch, J. D., Olausson, P., De La Garza, R. II., and Taylor, J. R. (2002). Impairments of reversal learning and response perseveration after repeated, intermittent cocaine administrations to monkeys. Neuropsychopharmacology 26, 183-190. doi: 10.1016/s0893-133x(01)00355-4

Jentsch, J. D., and Taylor, J. R. (1999). Impulsivity resulting from frontostriatal dysfunction in drug abuse: implications for the control of behavior by reward-related stimuli. Psychopharmacology 146, 373-390. doi: 10.1007/pl00 005483

Jett, J. D., and Morilak, D. A. (2013). Too much of a good thing: blocking noradrenergic facilitation in medial prefrontal cortex prevents the detrimental effects of chronic stress on cognition. Neuropsychopharmacology 38, 585-595. doi: 10.1038/npp.2012.216

Kessler, R. C., Davis, C. G., and Kendler, K. S. (1997). Childhood adversity and adult psychiatric disorder in the US National Comorbidity Survey. Psychol. Med. 27, 1101-1119. doi: 10.1017/s0033291797005588
Kessler, R. C., McGonagle, K. A., Swartz, M., Blazer, D. G., and Nelson, C. B. (1993). Sex and depression in the National Comorbidity Survey. I: lifetime prevalence, chronicity and recurrence. J. Affect. Disord. 29, 85-96. doi: 10.1016/0165-0327(93)90026-g

Korenbrot, C. C., Huhtaniemi, I. T., and Weiner, R. I. (1977). Preputial separation as an external sign of pubertal development in the male rat. Biol. Reprod. 17, 298-303. doi: 10.1095/biolreprod17.2.298

Kruzich, P. J., and Grandy, D. K. (2004). Dopamine $\mathrm{D}_{2}$ receptors mediate two-odor discrimination and reversal learning in $\mathrm{C} 57 \mathrm{BL} / 6$ mice. $B M C$ Neurosci. 5:12. doi: 10.1186/1471-2202-5-12

Kuehner, C. (2003). Gender differences in unipolar depression: an update of epidemiological findings and possible explanations. Acta Psychiatr. Scand. 108, 163-174. doi: 10.1034/j.1600-0447.2003.00204.x

Laughlin, R. E., Grant, T. L., Williams, R. W., and Jentsch, J. D. (2011). Genetic dissection of behavioral flexibility: reversal learning in mice. Biol. Psychiatry 69, 1109-1116. doi: 10.1016/j.biopsych.2011.01.014

Lee, B., Groman, S., London, E. D., and Jentsch, J. D. (2007). Dopamine D2/D3 receptors play a specific role in the reversal of a learned visual discrimination in monkeys. Neuropsychopharmacology 32, 2125-2134. doi: 10.1038/sj.npp.1301337

Leussis, M. P., and Andersen, S. L. (2008). Is adolescence a sensitive period for depression? Behavioral and neuroanatomical findings from a social stress model. Synapse 62, 22-30. doi: 10.1002/syn.20462

Leussis, M. P., Lawson, K., Stone, K., and Andersen, S. L. (2008). The enduring effects of an adolescent social stressor on synaptic density, part II: poststress reversal of synaptic loss in the cortex by adinazolam and MK-801. Synapse 62, 185-192. doi: 10.1002/syn.20483

Lewis, E. E., Dozier, M., Ackerman, J., and Sepulveda-Kozakowski, S. (2007). The effect of placement instability on adopted children's inhibitory control abilities and oppositional behavior. Dev. Psychol. 43, 1415-1427. doi: 10.1037/00121649.43.6.1415

Li, X., and Wolf, M. E. (2015). Multiple faces of BDNF in cocaine addiction. Behav. Brain Res. 0, 240-254. doi: 10.1016/j.bbr.2014.11.018

London, E. D., Ernst, M., Grant, S., Bonson, K., and Weinstein, A. (2000). Orbitofrontal cortex and human drug abuse: functional imaging. Cereb. Cortex 10, 334-342. doi: 10.1093/cercor/10.3.334

Lucantonio, F., Stalnaker, T. A., Shaham, Y., Niv, Y., and Schoenbaum, G. (2012). The impact of orbitofrontal dysfunction on cocaine addiction. Nat. Neurosci. 15, 358-366. doi: 10.1038/nn.3014

Lyons, D. M., Lopez, J. M., Yang, C., and Schatzberg, A. F. (2000). Stresslevel cortisol treatment impairs inhibitory control of behavior in monkeys. J. Neurosci. 20, 7816-7821.

MacMillan, H. L., Fleming, J. E., Streiner, D. L., Lin, E., Boyle, M. H., Jamieson, E., et al. (2001). Childhood abuse and lifetime psychopathology in a community sample. Am. J. Psychiatry 158, 1878-1883. doi: 10.1176/appi.ajp.158. 11.1878

Marshall, D. F., Passarotti, A. M., Ryan, K. A., Kamali, M., Saunders, E. F., Pester, B., et al. (2016). Deficient inhibitory control as an outcome of childhood trauma. Psychiatry Res. 235, 7-12. doi: 10.1016/j.psychres. 2015.12.013

Matochik, J. A., London, E. D., Eldreth, D. A., Cadet, J. L., and Bolla, K. I. (2003). Frontal cortical tissue composition in abstinent cocaine abusers: a magnetic resonance imaging study. Neuroimage 19, 1095-1102. doi: 10.1016/s10538119(03)00244-1

McCormick, C. M., and Mathews, I. Z. (2007). HPA function in adolescence: role of sex hormones in its regulation and the enduring consequences of exposure to stressors. Pharmacol. Biochem. Behav. 86, 220-233. doi: 10.1016/j.pbb.2006. 07.012

Moffitt, T. E., Arseneault, L., Belsky, D., Dickson, N., Hancox, R. J., Harrington, H., et al. (2011). A gradient of childhood self-control predicts health, wealth, and public safety. Proc. Natl. Acad. Sci. U S A 108, 2693-2698. doi: 10.1073/pnas. 1010076108

Monteggia, L. M., Luikart, B., Barrot, M., Theobold, D., Malkovska, I., Nef, S., et al. (2007). Brain-derived neurotrophic factor conditional knockouts show gender differences in depression-related behaviors. Biol. Psychiatry 61, 187-197. doi: 10.1016/j.biopsych.2006.03.021

Moreno-López, L., Perales, J. C., van Son, D., Albein-Urios, N., Soriano-Mas, C., Martinez-Gonzalez, J. M., et al. (2015). Cocaine use severity and cerebellar 
gray matter are associated with reversal learning deficits in cocaine-dependent individuals. Addict. Biol. 20, 546-566. doi: 10.1111/adb.12143

Mueller, S. C., Maheu, F. S., Dozier, M., Peloso, E., Mandell, D., Leibenluft, E., et al. (2010). Early-life stress is associated with impairment in cognitive control in adolescence: an fMRI study. Neuropsychologia 48, 3037-3044. doi: 10.1016/j. neuropsychologia.2010.06.013

Netherton, C., Goodyear, I., Tamplin, A., and Herbert, J. (2004). Salivary cortisol and dehydroepiandrosterone in relation to puberty and gender. Psychoneuroendocrinology 29, 125-140. doi: 10.1016/S0306-4530(02) 00150-6

Nigg, J. T., Wong, M. M., Martel, M. M., Jester, J. M., Puttler, L. I., Glass, J. M., et al. (2006). Poor response inhibition as a predictor of problem drinking and illicit drug use in adolescents at risk for alcoholism and other substance use disorders. J. Am. Acad. Child Adolesc. Psychiatry 45, 468-475. doi: 10.1097/01. chi.0000199028.76452.a9

Numakawa, T., Adachi, N., Richards, M., Chiba, S., and Kunugi, H. (2013). Brain-derived neurotrophic factor and glucocorticoids: reciprocal influence on the central nervous system. Neuroscience 239, 157-172. doi: 10.1016/j. neuroscience.2012.09.073

Petanjek, Z., Judaš, M., Šimic, G., Rasin, M. R., Uylings, H. B., Rakic, P., et al. (2011). Extraordinary neoteny of synaptic spines in the human prefrontal cortex. Proc. Natl. Acad. Sci. U S A 108, 13281-13286. doi: 10.1073/pnas. 1105108108

Pitts, E. G., Taylor, J. R., and Gourley, S. L. (2016). Prefrontal cortical BDNF: a regulatory key in cocaine- and food-reinforced behaviors. Neurobiol. Dis. 91, 326-335. doi: 10.1016/j.nbd.2016.02.021

Regner, M. F., Dalwani, M., Yamamoto, D., Perry, R. I., Sakai, J. T., Honce, J. M., et al. (2015). Sex differences in gray matter changes and brain-behavior relationships in patients with stimulant dependence. Radiology 277, 801-812. doi: 10.1148/radiol.2015142541

Ridley, R. M., Haystead, T. A., and Baker, H. F. (1981). An analysis of visual object reversal learning in the marmoset after amphetamine and haloperidol. Pharmacol. Biochem. Behav. 14, 345-351. doi: 10.1016/0091-3057(81)90401-9

Sacks, J. Y., McKendrick, K., and Banks, S. (2008). The impact of early trauma and abuse on residential substance abuse treatment outcomes for women. J. Subst. Abuse Treat. 34, 90-100. doi: 10.1016/j.jsat.2007.01.010

Sakata, K., Martinowich, K., Woo, N. H., Schloesser, R. J., Jimenez, D. V., Ji, Y., et al. (2013). Role of activity-dependent BDNF expression in hippocampalprefrontal cortical regulation of behavioral perseverance. Proc. Natl. Acad. Sci. U S A 110, 15103-15108. doi: 10.1073/pnas.1222872110

Schoenbaum, G., Saddoris, M. P., Ramus, S. J., Shaham, Y., and Setlow, B. (2004). Cocaine-experienced rats exhibit learning deficits in a task sensitive to orbitofrontal cortex lesions. Eur. J. Neurosci. 19, 1997-2002. doi: 10.1111/j. 1460-9568.2004.03274.x

Schwandt, M. L., Heilig, M., Hommer, D. W., George, D. T., and Ramchandani, V. A. (2013). Childhood trauma exposure and alcohol dependence severity in adulthood: mediation by emotional abuse severity and neuroticism. Alcohol. Clin. Exp. Res. 37, 984-992. doi: 10.1111/acer.12053

Selemon, L. D. (2013). A role for synaptic plasticity in the adolescent development of executive function. Transl. Psychiatry 3:e238. doi: 10.1038/tp.2013.7

Shapiro, L. P., Omar, M. H., Koleske, A. J., and Gourley, S. L. (2017a). Corticosteroid-induced dendrite loss and behavioral deficiencies can be blocked by activation of Abl2/Arg kinase. Mol. Cell. Neurosci. 85, 226-234. doi: 10.1016/j.mcn.2017.10.007

Shapiro, L. P., Parsons, R. G., Koleske, A. J., and Gourley, S. L. (2017b). Differential expression of cytoskeletal regulatory factors in the adolescent prefrontal cortex: implications for cortical development. J. Neurosci. Res. 95, 1123-1143. doi: 10.1002/jnr.23960

Simpson, T., and Miller, W. (2002). Concomitance between childhood sexual and physical abuse and substance use problems: a review. Clin. Psychol. Rev. 22, 27-77. doi: 10.1016/s0272-7358(00)00088-x

Skowron, E. A., Cipriano-Essel, E., Gatzke-Kopp, L. M., Teti, D. M., and Ammerman, R. T. (2014). Early adversity, RSA, and inhibitory control: evidence of children's neurobiological sensitivity to social context. Dev. Psychobiol. 56, 964-978. doi: 10.1002/dev.21175

Snyder, K. P., Barry, M., and Valentino, R. J. (2015). Cognitive impact of social stress and coping strategy throughout development. Psychopharmacology 232, 185-195. doi: 10.1007/s00213-014-3654-7
Spear, L. P. (2000). The adolescent brain and age-related behavioral manifestations. Neurosci. Biobehav. Rev. 24, 417-463. doi: 10.1016/s01497634(00)00014-2

Stroud, L. R., Papandonatos, G. D., Williamson, D. E., and Dahl, R. E. (2011). Sex differences in cortisol response to corticotropin releasing hormone challenge over puberty: pittsburgh Pediatric Neurobehavioral Studies. Psychoneuroendocrinology 36, 1226-1238. doi: 10.1016/j.psyneuen. 2011.02.017

Suri, D., and Vaidya, V. A. (2013). Glucocorticoid regulation of brain-derived neurotrophic factor: relevance to hippocampal structure and functional plasticity. Neuroscience 239, 196-213. doi: 10.1016/j.neuroscience.2012. 08.065

Tanabe, J., Tregellas, J. R., Dalwani, M., Thompson, L., Owens, E., Crowley, T., et al. (2009). Medial orbitofrontal cortex gray matter is reduced in abstinent substance-dependent individuals. Biol. Psychiatry 65, 160-164. doi: 10.1016/j. biopsych.2008.07.030

Tarter, R. E., Kirisci, L., Habeych, M., Reynolds, M., and Vanyukov, M. (2004). Neurobehavior disinhibition in childhood predisposes boys to substance use disorder by young adulthood: direct and mediated etiologic pathways. Drug Alcohol Depend. 73, 121-132. doi: 10.1016/j.drugalcdep.2003. 07.004

Teicher, M. H., and Samson, J. A. (2016). Annual research review: enduring neurobiological effects of childhood abuse and neglect. J. Child Psychol. Psychiatry 57, 241-266. doi: 10.1111/jcpp.12507

Vigers, A. J., Amin, D. S., Talley-Farnham, T., Gorski, J. A., Xu, B., and Jones, K. R. (2012). Sustained expression of brain-derived neurotrophic factor is required for the maintenance of dendritic spines and normal behavior. Neuroscience 212, 1-18. doi: 10.1016/j.neuroscience.2012.03.031

Viola, T. W., Wearick-Silva, L. E., De Azeredo, L. A., Centeno-Silva, A., Murphy, C., Mashall, P., et al. (2016). Increased cocaine-induced conditioned place preference during periadolescence in maternally separated male BALB/c mice: the role of cortical BDNF, microRNA-212, and MeCP2. Psychopharmacology 233, 3279-3288. doi: 10.1007/s00213-0164373-z

Warnault, V., Darcq, E., Morisot, N., Phamluong, K., Wilbrecht, L., Massa, S. M., et al. (2016). The BDNF valine 68 to methionine polymorphism increases compulsive alcohol drinking in mice that is reversed by tropomyosin receptor kinase B activation. Biol. Psychiatry 79, 463-473. doi: 10.1016/j.biopsych.2015. 06.007

Watt, M. J., Weber, M. A., Davies, S. R., and Forster, G. L. (2017). Impact of juvenile chronic stress on adult cortico-accumbal function: implications for cognition and addiction. Prog. Neuropsychopharmacol. Biol. Psychiatry 79, 136-154. doi: 10.1016/j.pnpbp.2017.06.015

Webster, M. J., Weickert, C. S., Herman, M. M., and Kleinman, J. E. (2002). BDNF mRNA expression during postnatal development, maturation and aging of the human prefrontal cortex. Dev. Brain Res. 139, 139-150. doi: 10.1016/s01653806(02)00540-0

Widom, C. S., and White, H. R. (1997). Problem behaviors in abused and neglected children grown-up: prevalence and co-occurrence of substance abuse, crime and violence. Crim. Behav. Ment. Health 7, 287-310. doi: 10.1002/ cbm.191

Winhusen, T., and Lewis, D. (2013). Sex differences in disinhibition and its relationship to physical abuse in a sample of stimulant-dependent patients. Drug Alcohol Depend. 129, 158-162. doi: 10.1016/j.drugalcdep.2012. 09.014

Wright, L. D., Hebert, K. E., and Perrot-Sinal, T. S. (2008). Periadolescent stress exposure exerts long-term effects on adult stress responding and expression of prefrontal dopamine receptors in male and female rats. Psychoneuroendocrinology 33, 130-142. doi: 10.1016/j.psyneuen.2007. 10.009

Xu, B., Zang, K., Ruff, N. L., Zhang, Y. A., McConnell, S. K., Stryker, M. P., et al. (2000). Cortical degeneration in the absence of neurotrophin signaling: dendritic retraction and neuronal loss after removal of the receptor TrkB. Neuron 26, 233-245. doi: 10.1016/S0896-6273(00)81153-8

Xu, H., Zhang, Y., Zhang, F., Yuan, S. N., Shao, F., and Wang, W. (2016). Effects of duloxetine treatment on cognitive flexibility and BDNF expression in the mPFC of adult male mice exposed to social stress during adolescence. Front. Mol. Neurosci. 9:95. doi: 10.3389/fnmol.2016.00095 
Yoshii, A., and Constantine-Paton, M. (2010). Postsynaptic BDNF-TrkB signaling in synapse maturation, plasticity, and disease. Dev. Neurobiol. 70, 304-322. doi: 10.1002/dneu.20765

Zhang, Y., Shao, F., Wang, Q., Xie, X., and Wang, W. (2017). Neuroplastic correlates in the mPFC underlying the impairment of stress-coping ability and cognitive flexibility in adult rats exposed to chronic mild stress during adolescence. Neural Plast. 2017:9382797. doi: 10.1155/2017/9382797

Zhang, J. C., Wu, J., Fujita, Y., Yao, W., Ren, Q., Yang, C., et al. (2014). Antidepressant effects of trkB ligands on depression-like behavior and dendritic changes in mice after inflammation. Int. J. Neuropsychopharmacol. 18:pyu077. doi: 10.1093/ijnp/pyu077

Zhang, F., Yuan, S., Shao, F., and Wang, W. (2016). Adolescent social defeat induced alterations in social behavior and cognitive flexibility in adult mice: effects of developmental stage and social condition. Front. Behav. Neurosci. 10:149. doi: 10.3389/fnbeh.2016.00149

Conflict of Interest Statement: The authors declare that the research was conducted in the absence of any commercial or financial relationships that could be construed as a potential conflict of interest.

Copyright (C) 2017 Barfield and Gourley. This is an open-access article distributed under the terms of the Creative Commons Attribution License (CC BY). The use, distribution or reproduction in other forums is permitted, provided the original author(s) or licensor are credited and that the original publication in this journal is cited, in accordance with accepted academic practice. No use, distribution or reproduction is permitted which does not comply with these terms. 